\title{
Dermatoglyphics, fetal growth, and insulin dependent diabetes in children under 5 years
}

\author{
J P H Shield, E J K Wadsworth, K Hobbs, J D Baum
}

Institute of Child Health, St Michael's Hill, Bristol BS2 8BJ J P H Shield E J K Wadsworth J D Baum

Fingerprint Bureau, Avon and Somerset Constabulary

K Hobbs

Correspondence to: Dr Shield.

Accepted 12 October 1994

\begin{abstract}
Examination of dermatoglyphic patterns in 112 diabetic children under 5 years and matched controls found no difference between the groups. Either those developing diabetes under 5 do not experience the same genetic and environmental conditions that influence its development in later life or the dermatoglyphic abnormalities described in later onset insulin dependent diabetes mellitus reflect the vast number of pattern formations available for study, which has inevitably led to some statistically significant associations. (Arch Dis Child 1995; 72: 159-160)
\end{abstract}

Keywords: dermatoglyphics, fetal growth, insulin dependent diabetes.

A relationship exists between fetal growth and the onset of disease in later life. A number of retrospective studies on adult cohorts from

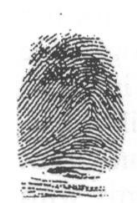

Arch

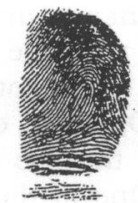

Loop

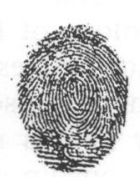

Whorl

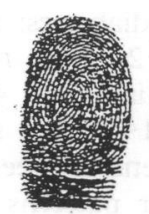

Twinned loop

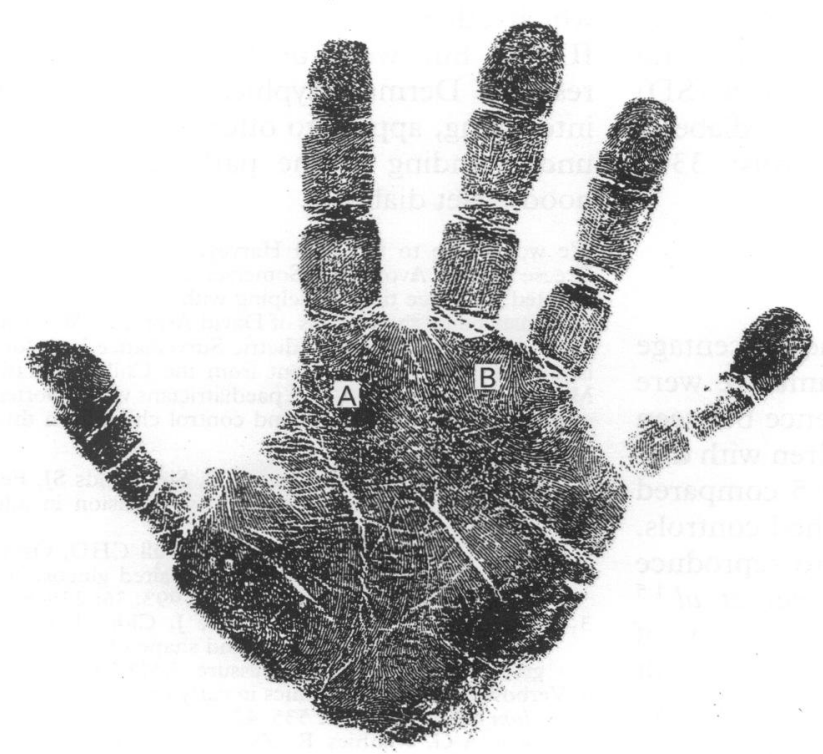

$A$ and $B$ triradii ( $A-B$ ridge count)

Illustrations from cases of the fingertip patterns analysed in the study, and palm print (at reduced size for publication) showing the $A$ and $B$ digital triradii used to define the $A-B$ ridge count (the number of ridges occurring in the second interdigital area between the two triradii).

Preston and Hertfordshire have reported an association between low birth weight and adult onset hypertension and non-insulin dependent diabetes. ${ }^{12}$ A recent study has suggested an association between the number of fingertip whorl patterns and later onset hypertension. ${ }^{3}$ It was implied that an individual's dermatoglyphics might reflect disordered fetal development.

Two studies have sought a relationship between dermatoglyphics and diabetes in adults. Verbov was unable to establish any such association within a whole population of patients with diabetes with onset under 40 (who would, by their age, have been mainly insulin dependent). However, the female patients considered as a separate group were significantly different from a control group in having a reduced $\mathrm{A}-\mathrm{B}$ ridge count on the right hand and a decreased number of whorl compared with arch patterns on the fingertips. ${ }^{4} \mathrm{~A}$ more recent study, solely concentrating on insulin dependent diabetes mellitus (IDDM) found, among other things, decreased A-B ridge counts in diabetics compared with controls but no differences in the fingertip patterns. This study suggested that individuals with IDDM may show characteristic dermatoglyphic features, reflecting either genetic or environmental factors acting in early pregnancy, which are also significant in the aetiology of the disease. ${ }^{5}$

To test these observations in relation to childhood onset diabetes, we studied the dermatoglyphics of children from the 1992 national cohort of children who developed diabetes under the age of 5 years compared with their age and sex matched non-diabetic controls.

\section{Patients and methods}

One hundred and seventy eight children with diabetes and 178 age and sex matched controls were each sent a modified 'scene of the crime' fingerprint sheet as used by the Avon and Somerset Police Fingerprint Bureau, together with an explanatory covering letter, ink pad, and a reply paid envelope. All the children had completed a questionnaire as part of the 1992 national case-control study of children under 5 years. The sheet coders, from the Avon and Somerset Police Fingerprint Bureau, did not know if the fingerprints were those of case or control children. As dermatoglyphic patterns are not very prominent in young children, only easily identified features such as fingertip patterns (arch, whorl, loop, etc) and the palmar A-B ridge counts (the number of ridges between the digital triradii in the second interdigital area between the fore and middle fingers) were analysed (figure). These features have previously been reported as significantly 
Percentage of each fingertip pattern found on the 10 hand digits for the diabetic cases and non-diabetic controls. Percentages in parentheses are the corresponding values from a population based study conducted by Cherrill at Scotland Yard $^{6}$

\begin{tabular}{|c|c|c|c|c|c|c|c|c|c|c|}
\hline & \multicolumn{5}{|l|}{ Left hand } & \multicolumn{5}{|c|}{ Right hand } \\
\hline & Thumb & Forefinger & $\begin{array}{l}\text { Middle } \\
\text { finger }\end{array}$ & $\begin{array}{l}\text { Ring } \\
\text { finger }\end{array}$ & $\begin{array}{l}\text { Little } \\
\text { finger }\end{array}$ & Thumb & Forefinger & $\begin{array}{l}\text { Middle } \\
\text { finger }\end{array}$ & $\begin{array}{l}\text { Ring } \\
\text { finger }\end{array}$ & $\begin{array}{l}\text { Little } \\
\text { finger }\end{array}$ \\
\hline \multicolumn{11}{|l|}{ Cases } \\
\hline Arches & $2(5)$ & $13(14)$ & $11(10)$ & $5(3)$ & $3(2)$ & $1(2)$ & $12(15)$ & $5(8)$ & $2(2)$ & $0(1)$ \\
\hline Loops & $57(66)$ & $53(55)$ & $69(72)$ & $70(63)$ & 78 (87) & $58(58)$ & $54(52)$ & $71(73)$ & $60(51)$ & $80(83)$ \\
\hline Whorls & $20(14)^{\star}$ & $20(23)$ & 9 (14) & $18(30)$ & $8(8)$ & $19(26)$ & $22(25)$ & $15(16)$ & $28(45)$ & $11(14)$ \\
\hline Twin loops & $8(14)$ & $3(6)$ & $3(3)$ & $3(3)$ & $0(2)$ & $10(13)$ & $3(6)$ & $3(2)$ & $4(1)$ & $1(1)$ \\
\hline Other & $0(<1)$ & $0(1)$ & $1(<1)$ & $0(<1)$ & $0(<1)$ & $0(<1)$ & $0(1)$ & $0(<1)$ & $0(<1)$ & $0(<1)$ \\
\hline Uncoded & $13(<1)$ & $11(1)$ & $7(1)$ & $4(<1)$ & $11(<1)$ & $12(<1)$ & $9(1)$ & $6(1)$ & $6(<1)$ & $8(<1)$ \\
\hline \multicolumn{11}{|l|}{ Controls } \\
\hline Arches & $2(5)$ & $14(14)$ & $9(10)$ & $3(3)$ & $1(2)$ & $2(2)$ & $13(15)$ & $9(8)$ & $2(2)$ & $1(1)$ \\
\hline Loops & $70(66)$ & $53(55)$ & $68(72)$ & $66(63)$ & 78 (87) & $59(58)$ & $59(52)$ & 79 (73) & $56(51)$ & 77 (83) \\
\hline Whorls & $5(14)^{\star}$ & $17(23)$ & $13(14)$ & $22(30)$ & $7(8)$ & $13(26)$ & $17(25)$ & $12(16)$ & $39(45)$ & $13(14)$ \\
\hline Twin loops & $8(14)$ & $3(6)$ & 0 (3) & $1(3)$ & $2(2)$ & 13 (13) & $2(6)$ & 0 (2) & 1 (1) & $1(1)$ \\
\hline Others & $0(<1)$ & $1(1)$ & $2(<1)$ & $0(<1)$ & $0(<1)$ & $0(<1)$ & $2(1)$ & $0(<1)$ & $1(<1)$ & $0(<1)$ \\
\hline Uncoded & $15(<1)$ & $12(1)$ & $8(1)$ & $8(<1)$ & $12(<1)$ & $13(<1)$ & $7(1)$ & $0(1)$ & $1(<1)$ & $8(<1)$ \\
\hline
\end{tabular}

${ }^{\star} \mathrm{p}=0 \cdot 02$

different in adults with IDDM compared with controls.

Data were analysed using the SPSS-PC package. The $\chi^{2}$ test was used for qualitative and Student's $t$ test for quantitative data analysis.

\section{Results}

One hundred and twelve $(63 \%)$ case and 98 $(55 \%)$ control children completed and returned fingerprint sheets. There was no difference between the combined fingertip patterns of the diabetic and control groups $\left(\chi^{2} 5 \cdot 2378,4 \mathrm{df}\right.$, not significant) nor in A-B ridge counts on either hand (right hand diabetics: mean (SD) $42 \cdot 8(5 \cdot 3)$, controls: $41 \cdot 2(5 \cdot 5), t=1 \cdot 89$, not significant; left hand diabetics: $43.4(5 \cdot 2)$, controls: $42 \cdot 1(5 \cdot 2), t=1 \cdot 69$, not significant). There was good agreement between our findings for individual finger patterns from both groups of children and the standard findings described by Cherrill ${ }^{6}$ (see table). The only difference noted was in the percentage of whorl patterns on the left thumb of diabetic children which was significantly higher than both the control group $\left(\chi^{2} 9 \cdot 85,3 \mathrm{df}, \mathrm{p}=0.02\right)$ and Cherrill's data. There was, incidentally, no significant difference between the mean (SD) birth weight of the children with diabetes compared with that of the controls: 3345 (539) g against 3374 (510) g.

\section{Discussion}

With the notable exception of the percentage of whorl patterns on the left thumb we were unable to demonstrate any difference between the basic dermatoglyphics of children with diabetes diagnosed under the age of 5 compared with a group of age and sex matched controls.

In particular we were unable to reproduce the findings of Verbov and Ziegler et al. ${ }^{45}$ Verbov described a decreased frequency of whorls and increased arches in a group of adult women with IDDM and decreased A-B ridge count. We were unable to show any such differences. Ziegler $e t$ al, in a group of adults with IDDM (mean age at diagnosis 18 years), found no fingertip pattern differences compared with control subjects but reported a decreased $\mathrm{A}-\mathrm{B}$ ridge count in both male and female diabetics (right hand mean values 31.3 and left hand $32 \cdot 3$ ). Our A-B ridge counts in young children with diabetes were no different from their age and sex matched controls, with mean values in both groups similar to the control group of Ziegler et al at 40.4 and 41.3 respectively.

Dermatoglyphic formation involves both genetic and environmental contributions with the process being completed by the 19th week of gestation. ${ }^{7}$ Godfrey et al have suggested that fingertip patterns are an indelible marker of impaired early fetal development. ${ }^{3}$ It seems likely that if it is a general truth that disordered early fetal development accounts in part for the aetiology of IDDM, then the dermatoglyphic abnormalities should be demonstrable in those with the onset of IDDM in early childhood. Our results indicate that no such consistent relationship exists. One of the problems with dermatoglyphic studies is the capacity to look at large numbers of variables within very complex formations, making statistically significant associations almost inevitable. We concentrated on the two fundamental areas in which others have reported associations with IDDM but were unable to reproduce the results. Dermatoglyphics, while essentially interesting, appear to offer little to further our understanding of the pathogenesis of childhood onset diabetes.

We would like to thank D Harvey, S Coombes, and Helen Creese at the Avon and Somerset Fingerprint bureau who devoted their free time to helping with this project. This study was financed by the Friends of David Ashmead. We would also like to thank the British Paediatric Surveillance Unit for its colaboration (funded by a grant from the Children Nationwide Medical Research Fund), the paediatricians who reported cases,
and the parents of the case and control children in this study.

1 Barker DJP, Bull AR, Osmond C, Simmonds SJ. Fetal and placental size and the risk of hypertension in adult life. $B M 7$ 1990; 301: 259-62.

2 Phipps K, Barker DJP, Hales CN, Fall CHD, Osmond C Clark PMS. Fetal growth and impaired glucose tolerance in men and women. Diabetologia 1993; 36: 225-8.

3 Godfrey KM, Barker DJP, Peace J, Cloke J, Osmond C Relationship of fingerprints and shape of the palm to fetal Relationship of fingerprints and shape of the palm to fetal

Verov $\mathrm{c}$. Hum Hered 1973; 23: 535-42.

5 Ziegler A-G, Mathies R, Ziegelmayer G, Baumgartl H-J, Rodewold A, Chopra V. Dermatoglyphics in type 1 diaRodewold A, Chopra V. Dermatoglyphics

6 Cherrill FR. The finger print system at Scotland Yard. London: HMSO, 1954 .

7 Mulvihill JJ, Smith DW. The genesis of dermatoglyphics. f Pediatr 1969; 75: 579-89. 